\title{
LOS DERECHOS HUMANOS ENTRE LA BIOÉTICA Y LA GENÉTICA
}

\author{
Salvador Darío Bergel*
}

\begin{abstract}
Resumen: La evolución operada en genética humana a partir de la década de los cincuenta, actuó como disparador en múltiples campos, en especial en los referidos a la bioética y al derecho. Muchos de los avances realizados pueden rozar la dignidad del hombre, a la par que impulsan la creación de nuevos derechos humanos.

En base a ello se analizan los impactos más significativos de la nueva genética sobre la sociedad: el peligro de una nueva eugenesia, la discriminación por razones genéticas, el manejo de la información genética, los problemas derivados de la investigación sobre el genoma, la apropiación del material genético humano; marcando algunos senderos a recorrer, a modo de conclusión.
\end{abstract}

Palabras clave: Genética, derechos humanos, bioética

\section{HUMAN RIGHTS: IN BETWEEN BIOETHICS AND GENETICS}

\begin{abstract}
The evolution of human genetics, from the fifties onwards, acted as a trigger for multiple fields, especially for those dealing with bioethics and law. Many of the advances accomplished may touch human dignity and, at the same time, they impel the creation of new human rights.

On the basis of these premises the author analyses the most significant impacts of the new genetics upon society: the danger of a new eugenism, genetic discrimination, manipulation of genetic information, problems derived from the investigation on the genome, the appropriation of human genetic material; indicating, in conclusion some paths to follow.
\end{abstract}

Key words: Genetics, human rights, bioethics

\section{OS DIREITOS HUMANOS ENTRE A BIOÉTICA E A GENÉTICA}

Resumo: A evolução ocorrida em genética humana a partir da década dos cinqüenta atuou como efeito gatilho em muitos campos do conhecimento, em especial, na bioética e no direito. Muitos dos avanços realizados podem atingir a dignidade do homem, ao mesmo tempo em que incrementam a criação de novos direitos humanos.

Tomando como base esses elementos, analisam-se os impactos mais significativos da nova genética sobre a sociedade: o perigo de nova eugenia, discriminação por razões genéticas, manuseio da informação genética, problemas derivados da investigação genômica, apropriação de material genético humano. Em forma de conclusão, são propostos alguns caminhos a percorrer.

Palabras chave: Genética, direitos humanos, bioética

\footnotetext{
Doctor en Ciencias Jurídicas y Sociales. Titular de la Cátedra UNESCO de Bioética (UBA), Buenos Aires, Argentina.

Correspondencia: s.bergel@ezabog.com.ar
} 
"El dominio médico y social de las posibilidades de previsión del destino biológico de los individuos, actualmente en pleno desarrollo, aparece como el más temible de los problemas éticos traídos por los progresos en genética. En el futuro la cuestión de la legitimidad y de los límites de una intervención sobre el patrimonio genético de una persona será probablemente de una creciente intensidad" (A.Kahn)(1)

\section{Introducción}

La bioética -tal como es sabido- surgió como disciplina dedicada al estudio de los problemas y dilemas éticos originados por los avances de las ciencias de la vida en la segunda mitad del siglo pasado. El término -acuñado por el oncólogo americano Potter- data de 1970, pero los problemas que llevaron a su nacimiento, así como las primeras reflexiones formuladas alrededor de los mismos, datan de la década de los cincuenta.

En los años que siguieron a la Segunda Guerra Mundial, fue dable advertir la toma de conciencia sobre dos grupos de problemas que tocan muy de cerca al hombre como protagonista de cambios llamados a tener profunda influencia en su futuro: por una parte, una formidable revolución en biología, que la perfilaba como la gran estrella del siglo y, por otra, la magnitud e irreversibilidad de los problemas medioambientales creados por procesos irracionales de crecimiento económico.

Temas de semejante magnitud e implicancias en los más diversos campos de la actividad humana no podían quedar librados a la sola especulación filosófica, por lo que se imponía un nuevo enfoque más abarcador con el auxilio de otras ramas del saber.
Potter señalaba que la bioética fue proyectada como una nueva disciplina que combina el conocimiento biológico con el conocimiento de los sistemas de valores humanos; lo que ratifica Diego Gracia al agregar que el ilustre oncólogo entendió la bioética como una nueva cultura, con el encuentro necesario entre los hechos, tal como hoy lo plantean las ciencias y en especial las ciencias de la vida y los valores, así como entre las ciencias y las humanidades(2).

Logros relevantes en la investigación científica en temas vinculados con el comienzo y fin de la vida, con técnicas de transplante de órganos, con la fecundación médica asistida, con la secuenciación del genoma humano, con la ingeniería genética, así como las revelaciones sobre el calentamiento global, la pérdida de la diversidad biológica, la desertificación -por nombrar algunos de los temas que ocuparon la atención de la sociedad en esos años- llamaron a una reflexión más profunda en su seno, en tanto comprometían al hombre en su dimensión más amplia.

Su análisis invitaba al trabajo inter y trans disciplinario, convocando investigadores de las más diversas ramas del saber: filósofos, médicos, biólogos, antropólogos, teólogos, juristas, etc., para ilustrar el necesario debate social. Aquí la interdisciplinaridad es más extrema que en cualquier otro lugar, pues la bioética requiere de las ciencias duras tanto como de las ciencias sociales y también de las prácticas, que no son ciencias en el mismo sentido, siendo más normativas que predictivas, tales como la filosofía, el derecho, la teología(3).

El cuadro arriba esbozado mostraba el flujo de un gran caudal de saberes nuevos vinculados con los diversos campos de la vida. Se asistía a un período fecundo en realizaciones con el avance de las ciencias y de las técnicas; que imbricados en un engranaje difícil de desarticular, generaron una real revolución del 
conocimiento. Las tecnociencias, se constituyeron así en uno de los objetivos centrales del debate social.

Este aluvión de ideas nuevas que, partiendo de las ciencias básicas, llevaba a las más variadas aplicaciones técnicas, ese constante y fecundo interactuar -prueba cabal de ello es el proceso que recorrió el proyecto de secuenciación del genoma- motivó dispares reacciones en el seno de la sociedad.

Junto a la creciente complejidad en la creación y manejo del conocimiento, fue dable advertir un cambio en la posición de la sociedad. De una actitud sumisa, alejada de un mundo que no le era demasiado familiar el mundo de la ciencia-, la sociedad avanzó exigiendo una creciente participación en la toma de decisiones relativas a problemas que, ya se advertía, comprometían valores inestimables del presente y del futuro.

El saber de los expertos fue puesto en sus justos límites(4) y la participación ciudadana se constituyó imperceptiblemente en una exigencia insoslayable para la toma de decisiones en políticas públicas relativas a estos temas. Los encendidos debates sobre alimentos y cultivos transgénicos, sobre clonación humana reproductiva y terapéutica, sobre eutanasia, sobre la investigación en embriones humanos, por sólo mencionar algunos ejemplos, trascienden largamente los cerrados círculos científicos para trasladarse a la sociedad en sus diversos estamentos.

Es cierto que la complejidad de los temas en debate los coloca cada vez más lejos de la comprensión del ciudadano medio; pero, no obstante ello, éste pugna por acercarse a su conocimiento, por desentrañar las implicancias de todo orden que pueden tener -tanto en el campo individual como en el social, tanto para el hombre de hoy como para las generaciones futuras- y por poder participar en las decisiones que se adopten para conservar y mantener el control social de las tecnociencias, en cuanto pueden afectar derechos fundamentales del individuo.

Aquí se advierte la necesidad de un enfoque inter y trans disciplinario.

El investigador podrá, en la caja de cristal de su laboratorio, llegar a crear una nueva técnica, realizar un descubrimiento o una invención para el ser humano, pero el análisis del impacto social que generará su aplicación escapa de sus manos. Esto queda reservado al amplio debate social que, por definición, compromete diversos saberes.

Conformamos sociedades pluralistas en las que conviven hombres que sustentan diversas creencias y pareceres lo que, necesariamente, debe conducir a que las decisiones fundamentales en temas que tocan aspectos viscerales de lo humano se tomen en base a un debate amplio y participativo.

La naturaleza, relevancia y dimensión de los problemas que trae a diario la investigación en las ciencias de la vida crea la necesidad de un debate permanente; debate que, partiendo de la información objetiva generada en los estamentos científicos, compromete a la sociedad en su conjunto.

Al hilo de estas reflexiones se ha señalado que "cuando la influencia de la ciencia y de la técnica es tan enorme que puede comprometer el pasado y el futuro de la vida humana, nuevos procedimientos de revelación y control distintos de los clásicos se hacen necesarios. No es suficiente aplicar rigurosos estándares éticos y jurídicos en el desarrollo de la investigación científica, sino que se requiere también la puesta en marcha de procedimientos que ensanchen la participación y deliberación de la sociedad favoreciendo asi la emergencia de vías más flexibles que las actuales para la legitimación de las decisiones públicas"(5). 
La bioética no nació como fruto de una reflexión académica, sino como una respuesta natural de la sociedad a una problemática que pugnaba por hallar nuevos cauces de expresión y otras formas de tratamiento con la intervención de nuevos protagonistas.

En su camino se vinculó al derecho y, desde entonces, recorrieron horizontes en búsqueda de respuestas comunes a temas trascendentes para el ser humano, traídos por el avance de las ciencias de la vida.

\section{El papel del derecho en esta trama}

Hoy se torna necesario, y hasta diríamos urgente, el asegurar la protección de los derechos fundamentales de la ciudadanía ante un escenario en el que se pueda advertir la fragilidad de su defensa frente a las conquistas de las ciencias de la vida, en tanto amenazan su libertad, su dignidad, su intimidad y su futuro.

Pero ni la necesidad ni la urgencia de estas exigencias pueden llevar a concebir que sólo las normas jurídicas, coactivamente impuestas, puedan alcanzar los fines propuestos. La sociedad -lo destaca Casado- debe premunirse de un bagaje de normas deontológicas y éticas que colaboren a la función de control y contribuyan a crear un entramado social cohesionado que, aplicando los principios de la bioética, los principios constitucionales y los derechos humanos, nos permita disponer de un adecuado marco de referencia en la toma de decisiones(6).

En el escenario actual se reconstituye una nueva imagen de la bioética: no sólo una "rama del saber" sino una multiforme experiencia de la formación del consenso en torno a problemas, elecciones morales, opciones políticas y jurídicas que se relacionan con el vínculo entre ciencia y valores del hombre(7).

En la formación de ese consenso juega un papel protagónico esencial el derecho como elemento ordenador de la sociedad y -en última instancia- como normativa en cuya elaboración no sólo juega el arbitrio del legislador. Si el derecho es norma -según lo entiende Kaufmann- entonces no se puede conformar con la legalidad, pues la norma exige moralidad(8). En esta exigencia de moralidad se da la conexión entre bioética y derecho.

El legislador, cuando la dimensión social del problema en el campo de las ciencias de la vida requiere de su intervención, crea normas de incuestionable contenido bioético (por ejemplo, las leyes francesas de bioética de 1994, y las distintas regulaciones nacionales sobre temas parciales: Alemania, Gran Bretaña, Holanda, Italia, etc.).

De esta conexión también nos habla la actitud de los jueces llamados a resolver los complejos problemas que trae el avance de las ciencias de la vida. Día a día se ven precisados a decidir sobre temas novedosos generados por las ciencias médicas que jamás pudieron ser imaginados, no obstante lo cual deben resolverlos por aquello que "el juez no puede dejar de pronunciarse so pretexto de silencio, oscuridad o insuficiencia de la ley". En estas situaciones recurren con frecuencia a los principios generales de la bioética, a instrumentos derivados del "derecho internacional de la bioética" o a la opinión de los Comités de Ética.

Es más, aún existiendo normas de derecho positivo aplicables al caso planteado, la fundamentación bioética dota a la resolución judicial de un mayor grado de aceptación social. Es que -en última instancia- los procedimientos a los que recurre la bioética, en especial el debate participativo y multidisciplinario, dota a cualquier acto jurisdiccional que se funde en ella de una mayor legitimación.

La reflexión bioética entronca con el principio fundamental de respeto a la dignidad humana, con los derechos a la vida, a la 
integridad física y moral de la persona, a la libertad e igualdad, a la no-sujeción de las personas a experimentos médicos que atenten contra sus derechos fundamentales, temas todos ellos de relevancia para el derecho constitucional que, en su conjunto, llevan a incluir las cuestiones bioéticas en lo que se ha dado en denominar el "bloque de constitucionalidad"(9).

Pero es más, la creciente preocupación a nivel internacional por los problemas generados por los avances de la biología y, en especial, de la medicina condujeron a conformar una incipiente rama del derecho: "El Derecho Internacional de la Bioética", que pretende conformar una serie de principios que escapan a la existencia de fronteras cerradas. La Convención Europea para la Protección de los Derechos Humanos y de la Dignidad del Ser Humano frente a las aplicaciones de la Biología y de la Medicina, y la Declaración Universal de la UNESCO sobre los Derechos del Hombre y el Genoma Humano constituyen dos sólidos soportes normativos de esta novedosa rama jurídica(10).

El primero de ellos, en tanto que es una Convención, integra formalmente el derecho internacional. En cuanto al segundo, si bien puede ofrecer algunas dudas, no resulta difícil insertarlo en el orden jurídico internacional, en tanto que, conforme lo enseña Gros Espiell, las declaraciones de los organismos internacionales adoptadas por consenso o por unanimidad pueden llegar a adquirir el carácter de formulación de principios de derecho o de cristalización de la costumbre internacional que los transforma en fuentes del derecho, tal como pasó con la Declaración Universal de los Derechos Humanos de 1984.

Derecho y bioética son, pues, disciplinas que se integran y se complementan para configurar una respuesta adulta y responsable de la sociedad ante los problemas y dilemas que nos ofrece el avance de las ciencias de la vida.

\section{Las implicancias éticas y jurídicas de la nueva genética}

La genética es el resultado de la síntesis de las leyes de la herencia establecida por Gregor Mendel (genética formal) y de estudios celulares y bioquímicos. Se trató en los comienzos de campos separados que, uniéndose, permitieron fundar la genética a partir del estudio de las moléculas(11).

Tuvo una evolución dispar ya que de 1865, año en que Mendel enuncia sus recordadas leyes, hasta 1940, se mantuvo en la genética de la transmisión y desde entonces evolucionó rápidamente incorporando la tecnología de los ácidos nucleicos, la transgénesis, la genómica (disección molecular de los genomas de los organismos vivos), la clonación de mamíferos por transferencia de núcleos(12).

Como disciplina científica se la observó con ciertas reservas y fue duramente cuestionada, en tanto que en los primeros pasos se la vinculó a la eugenesia. La humanidad no puede olvidar fácilmente las experiencias eugenésicas a las que fueron sometidos en el siglo pasado individuos y poblaciones, lo que marcó uno de los momentos más conflictivos entre ciencia y ética.

La utilización descarnada de los conocimientos científicos para discriminar poblaciones, para estigmatizar individuos o para esterilizarlos en pro de un supuesto mejoramiento de la especie, no constituye una buena carta de presentación de la genética. Es justificada la prevención con que fue observada y la condena social que generó, condena que comprendió a no pocos investigadores que se prestaron a realizar experiencias contrarias a la dignidad humana.

Genética, eugenesia y genocidio son palabras que no dejan de interrogar al hombre sobre la cuestión de su humanidad histórica porque están asociadas al origen de la noción 
de crimen contra la humanidad. Pero la genética toca también la humanidad del hombre en su dimensión espiritual. La mayor parte de las cuestiones que provoca conciernen tanto a la vida como a la muerte, es decir, a la finitud del ser humano(13).

La etapa que se abre en 1944, cuando Avery y colaboradores identificaron al ADN como base molecular de la herencia, es mucho más promisoria y fecunda en logros significativos para el bienestar de la humanidad, pero no por ello exentos de peligros para la libertad y la seguridad del individuo.

En las décadas del setenta y del ochenta se desarrollaron los ácidos nucleicos y las técnicas de "ingeniería genética" que posibilitaron la recombinación genética en la totalidad de los seres vivos, lo que dio nacimiento a lo que Daniel Nathaus denominó "la nueva genética", bajo cuyos auspicios se emprendieron proyectos tan relevantes como el Proyecto Genoma Humano.

El Proyecto Genoma Humano, junto a otros dirigidos a igual fin, marca uno de los momentos estelares de la nueva genética. La disección molecular del genoma abrió caminos que seguramente habrán de llevarnos a mejorar sustancialmente la salud humana, a diagnosticar tempranamente graves dolencias y a encarar una medicina a la medida de cada individuo, con todo lo que ello importa para el manejo de los medicamentos y para la optimización de sus aplicaciones.

Constituye un aporte fundamental de la ciencia puesta al servicio del hombre, lo que muestra el lado positivo de estos avances, pero junto a estos logros se presenta la sombra de los efectos negativos que fueron tempranamente advertidos al formarse los grupos ELSI, contemporáneamente al inicio del Proyecto Genoma Humano y otros similares, para investigar las implicancias éticas, jurídicas y sociales que generaban.
Es que el conocimiento profundo de las bases moleculares de la herencia arrastra toda una serie de cuestiones que pueden afectar derechos fundamentales del individuo o crearle graves inconvenientes en la vida de relación: la discriminación fundada en razones genéticas, el manejo distorsionado de la información genética, los desvíos en la investigación sobre el genoma humano, la apropiación del material genético y su utilización comercial, etc.

Es más, la creciente posibilidad de intervenir sobre el genoma modificando su información, no sólo en el individuo desde los primeros pasos de su gestación, sino también sobre su descendencia, abre un panorama de inusitados horizontes.

Al proyectarse la intervención sobre los descendientes el tema adquiere una dimensión universal, en la cual la esfera de los derechos subjetivos del individuo -sin dejar de admitir la importancia que se les debe reconocer- se ve desbordada por otros derechos de igual o superior entidad.

Aquí está en juego el destino de la especie humana y nuestra responsabilidad hacia las generaciones futuras, lo que ya se ha puesto en evidencia a través de normativas internacionales o nacionales que ponen estrictos límites a la manipulación y a la experimentación del genoma. El discurso de los "derechos a un genoma particular" en el contexto de la genética humana -lo señala Knoppers- es potencialmente volátil y peligroso(14).

Para preservar lo que es único al hombre, para preservar la pérdida de lo que es sagrado, para evitar que el cuerpo humano y sus partes constitutivas hasta las células mismas no se conviertan en productos del mercado u objeto de investigación científica no terapéutica, se debe apelar a la nueva función de los derechos del hombre de asegurar la mediación entre lo ético, lo jurídico y lo político, permitiendo trazar los límites entre lo justo y lo injusto y 
tendiendo hacia lo que se podría llamar una identidad jurídica de contenido variable(14, $p$. 152).

Sin llegar a desconocer el valor intrínseco de cada individuo como ser único e irrepetible, hay que pensar en la especie humana como reservorio de la información genética que la singulariza en el mundo de lo viviente.

En la consideración de estos temas -tan caros a la dimensión espiritual del hombre- es mucho lo que tiene que decir la bioética y, no menos, el derecho. Cuando el Proyecto Genoma Humano se hallaba en sus comienzos, en mayo de 1993 a iniciativa de Carlos M. Romeo Casabona, se realizó un encuentro en Bilbao en el que participaron más de cien especialistas de diversos países, en el que se analizó con profundidad el impacto de la investigación genómica desde la órbita jurídica y ética, parte de cuyos materiales conforman los cuatro volúmenes de El derecho ante el Genoma Humano.

En la declaración final del encuentro se señaló que la incidencia del conocimiento genético en el ser humano demandaba ya una determinada reflexión de los juristas para dar respuesta a los problemas que planteaba su utilización.

Los documentos internacionales acuñados para la protección de los derechos humanos, así como la bioética, parten del reconocimiento de la dignidad del ser humano y centran en ella sus reflexiones. En esta dirección la idea de inviolabilidad de la dignidad humana constituye la mejor expresión del consenso ético fundamental de nuestra $\operatorname{sociedad}(15)$.

Cuando hacen referencia a la dignidad del ser humano, cabe interpretar que se comprende tanto a la dignidad del hombre considerado en su individualidad, como a la dignidad común de la especie(14, p. 152)(16). Del reconocimiento de tal dignidad nacen los derechos humanos como atributos jurídicos aplicables a cualquier hombre por el solo hecho de serlo y sin ningún tipo de condicionamientos(17).

El espíritu de los derechos humanos -lo recuerda Hottois- es el de proteger siempre y en todo lugar la dignidad y la legalidad de los individuos, es decir, de hacer un llamado constante al respeto de la humanidad en el otro, quienquiera que sea y cualquiera sea su situación $(3, p .150)$.

Las formas en que la investigación científica puede afectar los derechos humanos -punto de confluencia entre bioética y derecho- son múltiples, en particular a partir de la nueva genética. El análisis puntualizado de estos temas excede largamente la propuesta de este trabajo, pero con el fin de conformar un cuadro de situación me permitiré tocar someramente los que considero más relevantes: los peligros de una nueva eugenesia, la discriminación por razones genéticas, el manejo distorsionado de la información genética, las investigaciones sobre el genoma, las prácticas contrarias a la dignidad del ser humano y la apropiación del genoma humano.

\section{a) La nueva eugenesia}

A partir de los años setenta se ha producido un espectacular avance en genética molecular, bioquímica y embriología cuyos logros se potenciaron, posibilitando poner en marcha nuevas técnicas vinculadas con la herencia, en particular la fecundación in vitro, las técnicas de ingeniería genética (ADN recombinante) y las que derivan de las investigaciones sobre la secuenciación del genoma humano, dando lugar a lo que denominamos "nueva eugenesia" 18 , 19).

Estas técnicas, en cuanto apuntan a desentrañar los misterios de la herencia y a cabalgar sobre ellos manipulando el genoma en más de una dirección, guardan una 
potencialidad capaz de afectar derechos fundamentales del individuo y de incidir negativamente en el futuro de la especie humana(20).

Mientras los movimientos eugenésicos de comienzos de siglo pasado, con un arsenal mucho más precario y eficaz, pugnaron por la mejora de la raza o la perfección de la especie, con un indudable trasfondo político, la nueva eugenesia se presenta como una cuestión vinculada al mejoramiento de la salud reproductiva(21).

Entre los instrumentos más eficaces con que cuenta tenemos la evolución operada en materia de diagnósticos genéticos. Hoy pueden brindar un mejor conocimiento no sólo de las enfermedades actuales vinculadas con la herencia, sino de las que nos suministra la medicina predictiva respecto a la aparición de futuras afecciones.

En el tema que analizamos cobran relevancia los diagnósticos vinculados con la reproducción, tales como los preconceptivos que se realizan en la pareja antes de tomar decisiones de procreación y, ya tomada esa decisión, los diagnósticos prenatales sobre el feto y el diagnóstico preimplantatorio obtenido del embrión antes de ser anidado en la mujer.

Todos éstos -tal como lo recuerda Romeo Casabona- son procedimientos vinculados en principio con la salud y con decisiones reproductivas de las parejas, pero -y esto es lo que más interesa aquí- pueden llevarse a cabo con fines estrictamente eugenésicos, de eugenesia negativa evitando la descendencia si se aprecia el riesgo de transmitir a la misma enfermedades hereditarias de las que son portadores los progenitores, o cuando el propio embrión o el feto son portadores de patologías graves $(21, p .9)$.

En el diagnóstico preimplantatorio pueden realizarse simultáneamente la eugenesia positiva (mediante la elección de los mejores embriones) y la negativa (mediante la eliminación de los restantes embriones). Ello ha llevado a evitar el nacimiento de niños con características que no justifican la interrupción del embarazo (incompatibilidad de rhesus, vectores de hemofilia, heterocigotos para una enfermedad recesiva) y se comienza a aplicar -según nos informa Testart- aparte de las enfermedades monogénicas a afecciones poligénicas, es decir, a factores de riesgo, dolencias cuya multiplicidad se irá precisando progresivamente mediante el conocimiento extensivo del genoma humano(22).

De igual forma, las técnicas de reproducción asistida pueden constituirse en un instrumento eficaz de eugenesia positiva en tanto posibilitan la selección de gametos o cigotos exentos de anomalías o portadores de las características deseadas.

A simple vista, puede advertirse que las situaciones sucintamente descriptas tienen gran relevancia para la reflexión ética, pero que, paralelamente, necesitan de la intervención del derecho cuando, más allá de la salud reproductiva, se intenten aplicar prácticas llamadas al "mejoramiento" del individuo o a determinar ciertos caracteres deseados. La concepción del genotipo "superior", "perfecto" -advierte Penchaszadeh- es absurda, pues la diversidad genética propia de la especie humana es el tesoro que permitió la evolución del hombre. El respeto a la diversidad humana no sólo es un principio ético fundamental, sino que es la mejor receta para la preservación de la vida humana en el planeta(23).

Si nos decidimos a utilizar la medicina, que prevé las predisposiciones para seleccionar individuos aceptables por nuestra sociedad y aquéllos que no lo serán, nos acoplaremos a una evolución humana en el mismo sentido y nos arriesgaremos a reducir la variabilidad genética, a crear una humanidad estandarizada 
y frágil. Nos expondremos a hacer del hombre, especie salvaje, una especie domesticada(24).

Hoy se torna necesario reconocer valores no genéticos con el fin de que no se defina a los individuos a través de sus características genéticas.

\section{b) Discriminación por razones genéticas}

El cúmulo de conocimientos adquiridos en torno al genoma humano llevó en muchos casos a exagerar las funciones de los genes en la herencia y en la determinación de las características físicas y psíquicas del ser humano pretendiendo vincular cada gen con un carácter o una anomalía, en una corriente traducida en un extremo condicionamiento del individuo a su información genética, que Abby Lippman describiera como "genetización de lo humano".

Hoy sabemos con mayor aval científico que ello no es así y que, sin menospreciar el papel que desempeñan los genes en la herencia, las características configurativas de la persona se deben a un complejo juego entre genes, los demás componentes celulares y el medioambiente.

Ya en los años cincuenta se había acuñado el término epigenética para destacar el ensamble de los genes con el medioambiente en el programa de desarrollo del ser humano.

Al concluir la primera etapa del Proyecto Genoma Humano con la secuenciación del genoma, se advirtió que el número de genes era muy inferior a lo que tradicionalmente se concibió, lo que llevó a explicar que un mismo gen codifica para diversas proteínas, ratificando cuanto hemos afirmado respecto a la complejidad de los mecanismos responsables de la evolución de un individuo.

No obstante ello, se llegó a vincular determinados genes con anomalías que aquejan al individuo y en un proceso en pleno desarrollo se trabaja sobre genes de susceptibilidad que pueden asociarse a las enfermedades más comunes que nos afectan: asma, cáncer, diabetes, hipertensión, esquizofrenia, depresión, ansiedad, etc.

Todo esto está dando paso a una nueva rama de la medicina: la medicina predictiva. Más allá del conocimiento de las dolencias actuales que afectan al sujeto será posible conocer con un cierto grado de aproximación la eventualidad de que una determinada enfermedad pueda aquejarlo durante el curso de su vida, lo cual puede contribuir a crear una línea divisoria que separaría a los sujetos sanos de los individuos con predisposición a contraer en el curso de su existencia determinadas enfermedades poligénicas o monogénicas(25).

Los SNIP's (polimorfimos de una sola base) pueden ser utilizados como marcadores para la identificación de factores genéticos de susceptibilidad genética, facilitando el conocimiento de las principales vías bioquímicas implicadas en su desarrollo. Desde luego que estos estudios no suponen detectar una enfermedad ya establecida, sino simplemente identificar factores de riesgo para su desarrollo(25, p. 19).

Es de imaginar la importancia que asume la posesión de tal información para determinadas relaciones sociales, en especial en los sectores laborales o de seguros.

En un mundo marcado por la desocupación o la precariedad del empleo como fenómenos ya incorporados a la economía corriente, tal información puede llevar a conformar un nuevo segmento de discriminados, sin horizontes de futuro.

De igual modo, la posesión de estos datos por las compañías de seguros -sobre todo las vinculadas con la prestación de servicios para 
la salud- pueden llevar a crear odiosas discriminaciones en perjuicio de numerosos individuos.

De allí la reacción social recogida en el artículo 7 de la Declaración de la UNESCO, en cuanto establece que nadie podrá ser objeto de discriminaciones fundadas en sus características genéticas cuyo objeto o efecto sea atentatorio contra los derechos y libertades fundamentales y el reconocimiento de su dignidad.

Hemos señalado anteriormente que los diversos rasgos físicos e intelectuales que presentan los seres humanos alimentan la diversidad, que debemos aceptarla y defenderla como un valor inherente a la propia vida, no como una fuente de estigmas individuales o sociales(26). Magistralmente, Bartha Knoppers ha resumido en una frase muy simple el vínculo que enraíza diversidad genética con igualdad: "todos los seres humanos son iguales porque cada uno de ellos difiere genéticamente de los demás".

El progreso genético abre formidables perspectivas en materia de retroceso de las enfermedades, pero crea dos riesgos aparentemente contradictorios: por un lado el riesgo de diferenciación y de discriminación, con una exigencia de igualdad $y$, por otro, un riesgo de uniformidad y de eliminación de la diversidad, lo que hace nacer un derecho a la diversidad.

El avance de la ciencia en este campo no puede ni debe ser detenido. Lo que se debe perfeccionar son los mecanismos sociales llamados a eliminar la discriminación por razones genéticas y a generar lazos más estrechos de solidaridad entre los individuos y los pueblos.

\section{c) El manejo de la información genética}

El conocimiento y el manejo de la información genética plantean desafíos inéditos para el derecho. Temas tales como la protección del derecho a la intimidad en este contexto, como el derecho a conocer o el de negarse a conocer la información genética que concierne al individuo, los relativos a la guarda y confidencialidad de estos datos, tienen una importancia crucial en tanto se relacionan con derechos fundamentales del ser humano.

Cabe advertir que la información genética relativa a un individuo puede constituirse en un instrumento de poder en manos de terceros, a la vez que en fuente de natural preocupación para el ser humano al convertirlo en un "hombre de cristal". De allí la necesidad de asegurar el control efectivo del sujeto sobre el proceso que parte de la obtención y culmina con la utilización de tal información(27).

En todas las etapas de ese delicado proceso de obtención y desvelamiento de la información, pasando por el ingreso de la misma a bases de datos, debe asegurarse la intervención del sujeto involucrado con el fin de obtener su consentimiento informado y poder ejercer el contralor indispensable para garantizar sus derechos de privacidad.

La información obtenida ha de ser pertinente para la finalidad perseguida por el análisis o el test, en resguardo de la autonomía del sujeto. Obtenida la información debe quedar en claro que la misma pertenece al sujeto y que cualquier utilización o disposición que se haga de allí en adelante debe igualmente contar con la conformidad del individuo en resguardo de sus derechos a la autodeterminación sobre sus datos personales, en tanto que la información genética debe necesariamente ser incluida en lo que modernamente se ha dado en denominar "información sensible".

La información genética puede extender la discriminación a nuevas categorías de personas, en tanto pueden ser redefinidas como "sujetos predispuestos" o "personas en riesgo" cuya potencial condición las diferencie de "lo normal". 
Se impone, pues, que la legislación, más allá de las normas que hoy puedan aplicarse por analogía, deba asegurar en forma explícita:

a) El derecho a la autodeterminación del sujeto traducido en el consentimiento libre e informado para todos los actos que se refieran a la obtención, circulación, desvelamiento y conservación de la información genética.

b) El derecho a conocer y a estar informado respecto de la información genética obtenida en análisis o test genéticos.

c) El derecho a no conocer tal información. Hoy día tan importante como el derecho a conocer es el derecho a no conocer, que debe ser respetado en toda su extensión a la mira de los efectos negativos que puede importar el conocimiento para la tranquilidad o equilibrio psíquico del sujeto. El conocimiento del posible problema de salud puede determinar graves situaciones de angustia, enfermedades psíquicas o psicosomáticas, así como provocar cambios vitales esenciales, sobre todo cuando el conocimiento de la posible enfermedad no va acompañado de la solución de ese problema(25, p. 24).

d) El derecho al control sobre el uso que pueda realizarse de su información depositada en bases de datos.

Los temas aquí someramente marcados exigen una revisión del contenido y alcance de la privacidad en el marco jurídico, con el innegable aporte bioético.

\section{d) Investigaciones sobre el genoma}

En el estado actual de la investigación genética es posible la manipulación del genoma humano, básicamente mediante técnicas que lo utilizan sin modificarlo y técnicas que apuntan a su modificación. Es de imaginar el enorme impacto que tienen en el campo de lo ético y de lo jurídico, ya que el empleo de estas técnicas no sólo pueden afectar al individuo sino a sus descendientes, lo cual nos traslada en un plano mucho más general a la especie humana.

Este es un campo en el que cabe manejarse con extrema prudencia en tanto puede entrar en colisión un derecho fundamental, cual es el de la libertad de investigación, con otros derechos de no menor envergadura.

Tal como lo enseña Kaufmann, no pueden los biólogos y éticos eludir simplemente los mandatos y prohibiciones de la ética invocando la libertad de la ciencia y la investigación, pues ésta tiene sus límites inmanentes en los valores del cuerpo, de la vida, la autodeterminación y la dignidad del hombre, y esas limitaciones subyacen no sólo a la aplicación tecnológica sino que existían ya en la investigación básica.

Si en algún lugar es válido que la ciencia no sólo esté tras la búsqueda de la verdad y el suministro de informaciones, sino que tiene frente a la comunidad una responsabilidad política y moral por sus actividades y sus soluciones, es precisamente en la órbita de la biotecnología(8, p. 535).

Desde las técnicas no invasoras hasta las que apuntan a modificaciones sustanciales en el genoma, tenemos una gama de supuestos que cada vez se ensancha en su número(28).

La resolución del Parlamento Europeo del 16-3-89 ya alertaba sobre los límites éticos y jurídicos de las investigaciones sobre el genoma. Desde entonces se ha avanzado considerablemente y al mismo ritmo de la investigación científica aumentó la preocupación de las sociedades sobre los problemas generados por lo que, en un concepto abarcador, denominamos "manipulación genética"(29).

Fruto de esa preocupación es la Declaración de la UNESCO que contiene un capítulo que 
comprende los artículos 10,11 y 12 , relativo a las investigaciones sobre el genoma y que a mi modo de ver- reflejan de modo bastante objetivo los límites de la aceptación social de tales investigaciones.

Como principio fundamental marca el cuadro dentro del cual podrán realizarse estas investigaciones: "ninguna investigación relativa al genoma humano ni sus aplicaciones en particular en la esfera de la biología, la genética y la medicina, podrán prevalecer sobre el respeto a los derechos humanos, a las libertades fundamentales y a la dignidad de los individuos o, si procede, de los grupos humanos".

A continuación, en forma genérica, prohíbe las prácticas contrarias a la dignidad del ser humano y brinda un solo ejemplo de tales prácticas: la clonación con fines reproductivos de seres humanos. En un sentido muy similar se pronuncia el protocolo adicional del Convenio sobre Derechos Humanos y Biomedicina, en el ámbito europeo.

Esta mención no es casual, en tanto nos está indicando un límite muy preciso y claro a la experimentación genética humana.

Ante el cúmulo de argumentos que desaconseja el empleo de estas técnicas en la reproducción humana entendemos que no tienen cabida las apelaciones dirigidas a la protección de supuestos derechos de quienes pretenden aplicarlas o a la libertad de investigación, ya que se encuentra en juego no sólo la dignidad y la integridad del individuo que puede ser concebido de esta forma, sino el propio destino de la especie humana.

Del hecho que el hombre conozca determinadas técnicas vinculadas con la genética humana no puede desprenderse que sea lícita la utilización de las mismas conforme a su capricho o a su conveniencia. Existe una responsabilidad social en el hombre de ciencia que no puede ser eludida, en tanto su labor trasciende sobradamente su campo de actuación.

No se puede admitir que sea indiferente a la conciencia social la creación de seres humanos a través de métodos experimentales (convirtiéndolos en verdaderos conejillos de indias), ni la alteración voluntaria de las leyes que gobiernan la herencia en la especie humana.

Muy distinto es el tema de las terapias génicas, aun cuando se refieran a intervenciones sobre las células germinales. Considero que sobre este particular se han dictado algunas regulaciones no suficientemente pensadas que se inspiran en criterios prohibitivos.

Tal como lo señala Knoppers sería lamentable que ante el Proyecto Genoma Humano fuéramos incapaces de distinguir las modificaciones correctas en la línea germinal respecto de las potenciales aplicaciones eugenésicas, pues las consecuencias de esa incapacidad podrían llegar a ser de incalculable valor(30). Por ello hemos señalado -con invalorable apoyo de Rodotàque la distinción fundamental que cabe hacer es la centrada en la finalidad: la que enfrenta el proyecto terapéutico frente al noterapéutico, sea en línea somática o en línea $\operatorname{germinal}(31)$.

En el último de los artículos de la Declaración de la UNESCO, referido al tema de las investigaciones sobre el genoma, se establece que tales investigaciones deben orientarse a aliviar el sufrimiento y mejorar la salud del individuo y de toda la humanidad, con lo cual se aparta de este campo toda aventura eugenésica.

La temática aquí expuesta es -seguramentela que mayores desarrollos ha motivado en la 
relación derecho-genética. Es natural que así sea en tanto entran en juego principios y valores fundamentales que están necesitados de una tutela adecuada.

Debemos aquí reiterar que las vías sancionatorias enderezadas a incriminar penalmente determinadas prácticas deben ser cuidadosamente pensadas, para no convertir a esta temática en un campo de enfrentamiento entre la libertad de investigación y el control social de los avances de la genética. Con toda prudencia el informe español sobre clonación marca con relación a estas técnicas conceptos que bien podrían aplicarse a la generalidad de las intervenciones sobre el genoma:

"el énfasis principal no debe ponerse en la prohibición o no-prohibición de ciertos procedimientos, sino en la provocación de la responsabilidad individual y colectiva.

El poder cada vez mayor de la ciencia y la tecnología exige no sólo una estricta reglamentación jurídica, sino y sobre todo el rearme moral de la sociedad y la promoción de la cultura de la responsabilidad"'(5, p. 261).

\section{e) La apropiación del material genético humano}

A medida que avanzaba al Proyecto Genoma Humano y otros similares dirigidos a igual finalidad, se advirtió la importancia económica de la utilización del material genético humano con fines diagnósticos y terapéuticos, lo que dio lugar a un intenso debate que aún se mantiene con gran intensidad.

Establecer los límites precisos entre la materia sujeta a apropiación (vía patentes) y la materia excluida, constituye un gran desafío en tanto, junto a aspectos científicos o jurídicos, juegan en forma preponderante intereses económicos de gran magnitud.
El gen -tal como gráficamente lo expresa Kahn- se ha convertido en materia prima de una industria en creciente desarrollo (la biotecnología) y las legislaciones tratan de adecuarse a esta nueva realidad, muchas veces con grave olvido de los principios éticos y jurídicos fundamentales(32).

Nadie discute que el cuerpo humano y sus partes son indisponibles y se encuentran fuera de comercio, y que el gen es parte -aún en su insignificante dimensión física- del cuerpo humano y debe por tanto ser sometido a iguales reglas.

A la luz de las investigaciones recientes particularmente las realizadas en el Proyecto Genoma Humano-, cabe extender el concepto de indisponibilidad del cuerpo y sus partes (como entidades físicas) a la información genética que poseen ${ }^{1}$.

En los hechos -lo hemos señalado- es mucho más relevante la información contenida en el genoma que un órgano, un tejido o un miembro. En tanto estas estructuras físicas pertenecen al individuo mientras que la información genética es común a la especie humana.

A pesar de ello y dando un salto más en la apropiación de lo natural, se pretende vincular la genómica a la ingeniería química estableciendo un equivalente entre moléculas de ADN y moléculas químicas, con el fin de aplicarles los principios aceptados por el derecho de propiedad industrial respecto de éstas.

En la práctica de las Oficinas de Patentes el gen es patentado como composición de materia o como producto, con todas las reivindicaciones

Bergel SD. Entre la dignidad y el mercado. En: Revista de Derecho y Genoma Humano $\mathrm{N}^{\circ} 16$ (en prensa). 
que usualmente se agregan a este tipo de patentes. Las reivindicaciones son particularmente importantes y extensas, en tanto cubren toda reproducción de la secuencia y todas las utilizaciones del gen y de la proteína, así como todas las aplicaciones potenciales diagnósticas y terapéuticas para usar en la investigación de nuevos medicamentos. Esto nos brinda una idea aproximada de los efectos negativos que genera la apropiación del gen o de la proteína(33).

El patentamiento de genes o secuencias de genes es lesivo a la dignidad del ser humano que queda instrumentalizado al extremo de admitirse que parte de la información genética que lo caracteriza pueda entrar en la esfera patrimonial de un sujeto. No ignoramos la importancia de los intereses que aquí entran en juego. Basta para tener una idea aproximada que sólo en los Estados Unidos, de 1980 al presente, se han otorgado más de veinte mil patentes sobre genes y moléculas vecinas, a lo que hay que adicionar cerca de veinticinco mil solicitudes de patentes en trámite(34).

No obstante, hay que reivindicar como cuestión de principio la inapropiabilidad del genoma humano. Destaco sobre el particular las conclusiones del grupo que me tocara presidir en el reciente Seminario Regional de Bioética convocado por la UNESCO (México 4-3-2002): "una profunda reflexión ética nos lleva a concluir que el genoma humano por sus elementos componentes como contenedores de la información genética, en tanto que son elementos comunes a todos los individuos que constituyen la familia humana no deben ser susceptibles de apropiación ni de aprovechamiento económico alguno. El tema de la apropiación del material genético humano, en especial por conducto de las patentes, excede el enfoque puramente jurídico. En tanto mediante estas vías se puede interferir la investigación científica o encarecer el precio de los medicamentos, test o análisis, el problema tiene un importante sesgo bioético".
Cabe aquí señalar que no cuestionamos la legitimidad de los derechos del inventor sobre su invento, derecho reconocido universalmente, pero esto no nos debe conducir al extremo de otorgar patentes sobre información genética humana, por no constituir una invención patentable y por afectar la dignidad de las personas.

Tal como hemos señalado, el derecho de patentes no puede ni debe quedar alejado de las consideraciones éticas, máxime cuando se trata de patentes vinculadas al ser humano(35).

\section{Conclusiones}

Pasada revista a los temas más relevantes que presenta la genética en su vínculo con la bioética, podemos establecer algunas conclusiones que sirvan para elaborar el carácter y los límites a la intervención del derecho en este campo.

¿Cuál es el papel que cabe asignar al derecho? ¿Deben "adaptarse" las normas jurídicas al constante fluir de problemas y dilemas que presenta la bioética en este terreno tan sensible para el ser humano?

¿Qué significado cabría otorgar a tal "adaptación"? Tal vez que el derecho evolucione detrás de los progresos científicos para proporcionar conceptos y técnicas que permitan un determinado control social.

En este caso -tal como lo señala Lavailleel derecho estaría colocado en el remolque de la ciencia y quedaría reducido a una función instrumental, vacío de toda referencia a los valores(36).

En esta postura positivista, el derecho se ahorraría la reflexión sobre el problema bioético que abandonaría a los investigadores, quedando fuera del campo del derecho. 
Esto, paralelamente, implica relegar al derecho a una función secundaria, meramente instrumental. El "bioderecho" no sería más que un instrumento que permitiría tratar las consecuencias sociales de los avances tecnológicos $(36, p$. 11).

Pero es del caso señalar que el derecho no puede agotarse en este contexto que lo degrada, en tanto importaría reconocerlo sólo como un conjunto de reglas, de categorías, de técnicas, olvidando que constituye un vehículo de un cierto número de valores.

Más allá de la función instrumental, el derecho expresa los valores fundamentales de una sociedad. Cuando una norma jurídica prohíbe la terapia génica en línea germinal, la experimentación con embriones, la clonación reproductiva humana, no sólo pretende regular determinadas situaciones que se presentan como novedosas en el campo de la ciencia, sino que paralelamente está expresando los valores de una sociedad determinada en un momento dado.

Bioética y derecho deben caminar conjuntamente para que los derechos fundamentales del hombre no se conviertan en letra muerta, arrastrados por una revolución científica que, sin prisa y sin pausa, avanza en forma avasalladora.

Cuando nos acercamos al mundo de la nueva genética con la multiplicidad y variedad de problemas que presenta, no podemos dejar de considerar a los derechos humanos como guía y faro cuya presencia ilumina el debate social y dirige sus pasos.

Cuanto se relaciona con la genética humana roza a la dignidad del hombre y, por tanto, a los derechos humanos que pretenden juridificar este valor supremo. Desde hace medio siglo la problemática de la bioética ha llegado a confundirse con la problemática de los derechos humanos(3 p. 213).

Toda una serie de nuevos derechos -algunos ya consolidados y otros en proceso de serlotales como el derecho a la protección del genoma humano contra prácticas contrarias a la dignidad del individuo, a la autodeterminación genética, a la privacidad genética, a la no-discriminación por razones genéticas, al consentimiento libre e informado para la realización de estudios genéticos, etc., conforman una nueva dimensión de los Derechos Humanos, categoría histórica que permanentemente en su camino fue adaptándose a los requerimientos y a las necesidades del momento, para proteger al hombre en su dignidad y en su libertad.

De lo que se trata hoy es que el avasallador avance de las tecnociencias no se dé afectando derechos fundamentales del individuo o desconociendo su dignidad y, en esta tarea, la bioética y el derecho tienen mucho que decir y que hacer. Es lo que espera una sociedad adulta que no desea permanecer ajena al debate de temas fundamentales que hacen referencia a su presente y al mundo que deberán habitar futuras generaciones. 


\section{Referencias}

1. Kahn A. Génétique, médecine et société. Comité Consultatif de Bioéthique de Belgique: Hérédité, Tests génétiques et société. Bruselas: De Boeck Université; 2001: 1.

2. Gracia D. Fundamentación y enseñanza de la bioética. Tomo I. Bogotá: Editorial El Búho; 1998: 30.

3. Hottois G. Bioética y Derechos Humanos. En: Escobar T, ed. Bioética y Derechos Humanos. Bogotá: Ediciones El Bosque; 1998: 150.

4. Boistard P. Expertise scientifique et débat démocratique. En: Michaud Y, dir. Qu'est la vie? París: Odile Jacob; 2000: 223.

5. Fundación de las Ciencias de la Salud - Instituto de Bioética. Informe sobre clonación. Madrid: Editorial Doce Calles SL; 1999: 254.

6. Casado M. La bioética ante las nuevas tecnologías genéticas. En: Casado M, González D, eds. Los retos de la genética en el Siglo XXI: genética y bioética. Barcelona: Ediciones Universitat de Barcelona; 1998: 15.

7. Zatti P. Verso un diritto per la bioetica. En: Mazzoni CM. Bioetica e diritto. Bologna: Edit. Il Mulino; 1998: 63.

8. Kaufmann A. Filosofia del Derecho. Bogotá: Editorial Universidad Externado de Colombia; 1995: 395.

9. Gros Espiell H. Constitución y bioética. En: Romeo Casabona CM. Derecho médico y bioética. Granada: Ediciones Comares; 1998: 139.

10. Lenoir N, Mathieu B. Les normes internationales de la bioéthique. París: PUF; 1998: 7.

11. Auffray CH, Jacquard A. Dictionnaire de la biologie. París: Flammarion; 1998: 115.

12. Lacadena JR. Las intervenciones en el genoma humano: un enfoque genético. En: Romeo Casabona CM. Genética y Derecho Penal. Granada: Ediciones Comares; 2001: 2.

13. Mattei JF, coord. Le génome humain. Strasbourg: Éditorial du Conseil de l’Europe; 2001: 11.

14. Knoppers BM. La génétique humaine: patrimoine et protection. En: Gros F, Huber G, eds. Vers un antidestin? Paris: Odile Jacob; 1992: 141.

15. Honnefelder L. Genética humana e dignidade do homme. En: De Boni J, Salzano Y, org. Etica e Genética. Porto Alegre: Edipurcs; 1998: 87.

16. Mathieu B. Génome humain et droits fondamentaux. París: Economica; 2000: 91.

17. Cortina A. Ética sin moral. Madrid: Tecnos; 1995: 247.

18. Iañez Pareja E. Retos éticos ante la nueva eugenesia. En: Romeo Casabona CM, ed. La eugenesia hoy. Bilbao: Ediciones Comares; 1999: 197. 
19. Beck-Gernsheim E. La base genética como materia prima y no como destino. Tecnología genética. Montevideo: Goethe Institut; 2000: 19.

20. Torbjorn T. Genética humana y el fantasma nazi. Perspectivas Bioéticas. Buenos Aires 2001; 11: 89.

21. Romeo Casabona CM. Las prácticas eugenésicas: nuevas perspectivas. En: Romeo Casabona CM, ed. La eugenesia hoy. Bilbao: Ediciones Comares; 1999: 3.

22. Testard J. La eugenesia médica: una cuestión de actualidad. Revista de Derecho y Genoma Humano 1998; 8 (enero-junio): 21.

23. Penchaszadeh V. Aspectos éticos en genética médica. En: Bergel S, Cantú JM, org. Bioética y Genética. Buenos Aires: Editorial Ciudad Argentina; 2000: 304.

24. Papiernik E. Vers un nouvel eugenisme? En: Gros F, Huber G, eds. Vers un anti-destin? Paris: Odile Jacob; 1992: 116.

25. Corcoy M. Medicina predictiva y discriminación. En: Medicina predictiva y discriminación. Barcelona: Fundación V. Grifols i Lucas; 2001: 24

26. Bergel SD. Genoma Humano: cómo y qué legislar. La Ley. Buenos Aires: 2001(7-12); 235:1

27. Knoppers BM. Réflexion éthique: pour une éthique renouvelée de la prédiction génétique. Comité Consultatif National d'éthique pour les sciences de la vie et de la santé, génétique et médecine. París: Éditorial La Documentation Française; 1997: 169.

28. Lacadena JR. Manipulación genética. En: Gafo J, ed. Fundamentación de bioética y nueva genética. Madrid: Universidad Pontificia Comillas; 1988: 150.

29. Parlamento Europeo. Problemas éticos y jurídicos de la manipulación genética y de la fecundación artificial humana. Luxemburgo1990: 9.

30. Blázquez Ruiz E. Derechos Humanos y eugenesia. En: Romeo Casabona CM, ed. La eugenesia hoy. Bilbao: Ediciones Comares; 1999: 275.

31. Rodotà S. Tecnologie e Diritto. Bologna: Il Mulino; 1995: 163.

32. Kahn A. Et l'homme dans tout ça? Paris: Nil Editions; 2000: XIII.

33. Bergel SD. La patentabilidad de los descubrimientos genéticos. El Derecho. Buenos Aires 18-12; 2001: 1 .

34. Doll JJ. Talking Gene Patents. Scientific American. August 2001: 20.

35. Bergel SD. Patentabilidad del material genético humano. Implicancias éticas y jurídicas. Revista de Derecho y Genoma Humano. Bilbao 2001; 15: 35.

36. Lavaille C. De la difficulté à légiférer sur le vivant. En: Neikink C, dir. De la Bioéthique au biodroit. Paris: LGDJ; 1994: 11. 